\title{
FENOMENOLOGÍA
}

\section{LA EXTRAÑA VIRTUD}

\author{
RaFa PAscual
}

A mi madre.

\begin{abstract}
Me acordé de Sulayma
cuando el ardor del combate

era igual que el de mi cuerpo

al separarse de ella.

Entonces crei ver,

entre las lanzas, sus pechos

y cuando se inclinaron hacia mi

las abracé.
\end{abstract}

Abu-l-Hassan b. al- Qabturnuh.

Sulayma

\section{DONDE SE DA FE DE LA EXISTENCIA DE DOÑA CASTA, HIJA DEL CONDE DE LA VILLA DE FRANQUEZA}

Que ensarten mi lengua en la pluma que este servidor sostiene y en las calderas del averno se queme si miento al decir que no existía en aquellos tiempos que la leyenda evoca doncella más fermosa que lucero alguno del cielo mas a la par amarga de tan estrecha virtud. Pues más fácil resultaria que camello o bestia aún mayor por el ojo de una aguja penetrase que en la flor de su encanto envainase la espada de su amor cualquier caballero galante que ante la dama fuera llegado para hacerle la corte -y bien sabe éste que escribe que fueron muchos los que tal empresa intentaron-, pues su seso sobre el cuerpo había impuesto que de los goces de la carne se privara, por considerarlo pecado de esos a los que al fuego arroja las almas cuando es llegada nuestra hora. $Y$ a que tales privaciones fue inducida por su padre, el conde de la Villa de Franqueza, ayudado por su grey de maestros y confesores. Fue el tal conde allá por sus tiempos mozos hombre bravucón y libertino -amén de putero y jugadorque arrepentido de sus correrias quiso educar en la virtud más estricta a su hija, pagando con privaciones ajenas sus pecados de juventud.

La belleza de la niña no era secreto alguno pues habiase corrido la voz más allá de los lindes del pueblo por todo aquel que la había visto en alguna ocasión el que la hija del conde tenía una mirada de azúcar bajo el manto de ceniza que era su pelo negro como el carbón, y otras galanterias más que, si bien fue la imaginación del populacho quien las añadió, a pesar de inventadas le iban a la par y aún se quedaban cortas. Atraídos por los rumores, numerosos pretendientes fueron fríamente rechazados por la bella Casta - que así se llamaba la dama-, saliendo de casa del Conde con el rabo entre las piernas como un can apedreado y con el alma herida por el no recibido, pues habian comprobado que los rumores no eran del todo verdad: la moza estaba aún más buena. Y es que en todos ellos veía oscuras intenciones que tras bellas palabras escondian —entre promesas de amor eterno- un si te he visto no me acuerdo, según ella creía entender. Y tantos caballeros acabaron rendidos que tanta rectitud famosa se hizo, y el pueblo acabó cantando la coplilla que a continuación escribo:

Tiene esta Villa una moza y en su vientre hay una breva que aquel que la quiere probar se las ve y se las desea. 
Mas al contrario de lo que muchos se piensan, aliviado respiraba su padre al ver a cada aspirante ignorado tomar el portalón. Pues no le importaba al Conde que quedase Casta soltera y sin heredero que ofrecerle, pues en ella veía el padre su carta de salvación: no pocas veces se imaginara éste quemándose en el Infierno o aguantando martirio en el Purgatorio hasta que el día de subir al Cielo a Casta le llegase y los Santos, querubines y demás corte celestial boquiabiertos comprobasen el resplandor de la pureza intacta que su padre le inculcó.

- ¡Por los Cielos que el artífice de tanto candor no ha de hallarse en el Infierno, y si así se tratase ha de deberse a un error! - exclamarían conmovidos al ver en su sitio el pétalo a la niña.

$Y$ según se seguía imaginando -ahora más aliviado- una mano de lo Alto le sería tendida para subir con su hija y disfrutar de los vicios que en vida abandonara, y allí fueran permitidos, tras media vida de rectitud.

Y así transcurría la vida, para que el lector se haga una idea, de la bella Casta, de la que más tarde se hablará.

\section{DONDE SE HABLA DEL CABALLERO RUINUÑO Y LA DECISIÓN QUE TOMÓ DE COMPROBAR LA FERMOSURA DE LA BELLA CASTA}

Vivía por aquellos lugares un caballero gandul y juerguista, más amigo del buen vino y de mejor compañía que de heróicas gestas que cubrieran de heridas su cuerpo y de gloria a su señor. Pues había alcanzado dicho título de caballero merced a su padre, señor de un villorrio de los muchos que sembraban el mapa de Castilla, fiel vasallo del rey que fue en sus tiempos mozos ahuyentando con mandobles de espada al moro infiel que ocupaba la tierra santa en la que ahora moraban. Y pese a haber salido vivo de las varias batallas en las que tomó parte y los beneficios que a la larga le proporcionó, no dudó desde el primer momento en hacer uso de sus influencias para evitar que su hijo, Ruinuño, nunca fuera requerido para las ofensivas que contra las tierras agarenas del sur eran tomadas por el rey Alfonso. Y es que no estaba dispuesto a perder a su único hijo, pues con el brazo que a él mismo le rebanaron en la guerra ya había rendido bastante tributo a Dios y al Rey tanto por su parte como por la de su hijo ya que, conocedor como era de la barbarie que de los hombres se apodera en el campo de batalla, nada le decía que no fuera el pescuezo lo que le podrían arrebatar a su vástago. Dicho esto, se adivina que la única sangre que acarició la espada de Ruinuño fue la del cochino el día de su matanza y la coraza mas dura atravesada un costal relleno de arena que hacía las veces de enemigo imaginario.

No estaba a disgusto el tal caballero -como ya se ha dicho antes- con las esperanzas que sobre él había depositado su padre y, con fingido malhumor, haciale ver que se conformaba con su vida pasiva de "irreductible valladar de la retaguardia", pues viendo los estragos que la vida guerrera causó sobre su progenitor, se le había metido el miedo en el cuerpo y la piel se le erizaba con solo pensar que los afanes guerreros le podrían obligar a disfrutar de los placeres de la vida con un solo brazo, e incluso privarlo de ellos.

Esta actitud se veía reforzada por el trato frecuente que mantenía con un pobre diablo de nombre desconocido y al que todos llamaban "el Cardenal" pues, según decía éste, tiempo atrás había sido fraile en un monasterio tan apartado que a nadie le sonaba el nombre.

- ¿Y cómo es que su santidad abandonó los hábitos para descender al infierno de la tentación? -solía decir su auditorio, las más de las veces bajo los efectos de una jarra de buen vino.

- Pues porque, habiendo adquirido tanta sabiduría como adquirí, consideré un desperdicio el guardarme tales tesoros del conocimiento para 
mí solo y que no había mejor forma de servir a nuestro Señor que haciendo partícipe de mi sabiduría a aquellos hermanos que por una jarra de vino $y$ algo que echarme al estómago tengan a bien escuchar mis historias.

$Y$ así comenzaba a hablarles de religión y filosofía y tenian sus palabras algo de verdad y el resto de mentira, y aunque al principio era consciente de tales falsedades a fuerza de reiterarlas acabó creyéndolas él mismo, y si alguna cuestión le planteaba duda sobre su veracidad, solía decirse:

- Es igual, pues si Fulano no dijo tal cosa, a buen seguro que se le olvidó escribirla o la hubiera dicho de haber vivido más años.

$Y$ lo aceptaba como verdad de tal forma que sin dudarlo en el fuego pondría la mano convencido de que no se quemaria.

De esta manera, las risas que al principio provocaban sus peroratas tornáronse en respeto y admiración por parte de las gentes incultas que formaban su auditorio, que incluso acudían a él para solucionar pequeñas rencillas entre vecinos, obteniendo éstos un dudoso veredicto y él su sustento por un día al menos.

Hacíase llamar Sastenillo, diminutivo que era -según él-de Sastenón, el gigante que -según el también- había no sólo logrado escapar de la Caverna Platónica, sino también sobrevivir a la impresión que supuso exponerse de sopetón a las maravillas ignotas del mundo exterior. Escuchaba la plebe la fábula de su nombre y sentíanse como dicho gigante: maravillados ante aquel hombrecillo orondo que les abría los ojos al mundo de las ideas.

Hallábase cierto día el tal Cardenal, o Sastenillo, o como se llame, tirado por el camino que llevaba al castillo del padre de Ruinuño de tal guisa que más bien parecía un ecce- homo: blancas las bolas de los ojos; la lengua, sobresaliente, babeando a un costado de la boca, y una caperuza de sangre seca sobre la testa. Pasaba por aquel lugar el joven Ruinuño a lomos de su caballo y, viendo el estado en el que se encontraba aquel pobre hombre, bajose de su montura para proporcionarle el socorro necesario. Mas viendo que éste se levantó del suelo nada más poner un pie en tierra, sospechó el caballero -que no por holgazán tenía un pelo de tonto- que aquel hombre no estaba tan mal como aparentaba y más podía deberse tan penoso estado a sus ganas de broma o de engañar a las gentes de buena voluntad. Y no fue la ausencia de herida sobre la prominente calva -que tal vez la habría sufrido un cerdo o una vaca- sino que, casi llorando, le dijera que unos malhechores le habían robado su mula y todo su dinero, pues era más posible que aquel resucitado sangrase sin tener herida alguna que semejante piojoso poseyese oro y cabalgadura que robarle. No dudó Ruinuño en proporcionarle la paliza que decía haber recibido, para que la próxima vez tuviera a bien considerar las consecuencias de su oficio antes de intentar engañar a cualquier desgraciado. Mas antes de hacer justicia, preguntole Ruinuño con airado enojo, para ver cómo reaccionaba:

-Mas ¿qué clase de garrote es aquel que produce sangre sin brecha?

E intuyendo Sastenillo la manta de palos que se le avecinaba, echose las manos a la cabeza y, cayendo de rodillas en tierra, comenzó a exclamar:

- ¡Milagro! ¡Milagro! ¡Nuestro Señor recompensa mi apostólica labor dejándome vivo y borrando de mi testa la firma del enemigo!

Aquellas palabras hubieran bastado para que una tormenta de coces se abalanzase sobre el costillar del hombrecillo, mas causaron tanta gracia en el caballero que en lugar de darle su merecido lo acompañó a su castillo y le proporcionó alojamiento -aunque eso sí: sin seguirle la corriente a la historia del milagro-, pues habia pensado que no sería mala idea analizar y aprender de la naturaleza ladina del supuesto apaleado. Y no se arrepintió de su decisión, pues amparado en el "pozo de sabiduría" que Sastenillo se acreditaba encontraba 
siempre Ruinuño las palabras que buscaba escuchar: y no eran estas más que las que justificaban su vida regalada y dedicada al goce. Y no sólo esto: era también el antiguo religioso conocedor de los lugares en los que se conjugaban los mejores vinos con las hembras más condescendientes, y a tales sitios solía llevarse Satenillo a su amigo Ruinuño para que sintiera en carne propia lo que los nobles romanos llamaban el otium cum classis, mostrándole cuán pecaminoso podría ser el despreciar tales creaciones del Señor por la cabezonería que tenía la nobleza en desperdiciar sus vidas peleándose con el vecino.

$Y$ con el paso de los días hicieronse ambos inseparables, pues si el uno aposento y comida obtenía de tan curiosa amistad, hallaba el otro el sustento moral para su vida licenciosa, amén del acceso a ciertos lugares a los que más por su condición de noble que por el desconocimiento que de estos tenía, pasar le era dificultoso, de no ser por la compañia, artimañas y disfraces de su fiel amigo.

\section{DONDE RUINUÑO HACE SABER A SAS- TENILLO DE SUS INQUIETUDES Y EL CON- SEJO QUE RECIBE DE ESTE}

Cierto día en el que se encontraban paseando por los jardines del castillo Ruinuño y Sastenillo, dijo el caballero a su amigo:

- Fiel Sastenillo; quiero que sepas de una pena que mi ánimo ensombrece desde hace tiempo y, aunque por hombre juicioso te tengo, dudo, por mucho que me pese, que exista solución.

Escuchábale con suma atención el falso doctor, sorprendido por el tono sombrío que su señor empleaba, y que atribuyó a un dolor de cabeza causado por los excesos del día anterior.

- En tu compañía, buen amigo, he catado la mesa, vinos y juego del vulgo $y$, si como tú bien sabes, no son nada despreciables pues mi espíritu no ha hecho ascos, aunque los placeres de los nobles tampoco son mancos. Mas iay, fiel
Sastenillo!, de todas las cosas hay una que provoca mi extravio y, por lejana, mi nobleza pesa como un castigo y sólo de recordarlo desvarío pues, ipara qué me sirve la razón si de ella han hecho presa aquellas mujeres plebeyas que en las noches de vino y juerga me amaron con tanta pasión?

Miró de reojo Sastenillo a su señor y para sus adentros se dijo: "la próxima vez, vigilaré que beba menos", y sin interrumpir el paso, siguió escuchando con atención:

- Llegado el momento será en que deba tomar la mano de una noble doncella para que mi esposa sea y una vez que me vea casado, y con ello privado de los presentes goces, ¿cómo con ella podré gozar? Si no habéis visto ninguna de estas niñas nobles, yo os las describiré, para que entencláis mis razones: si bien todas son unas pusilánimes y pálidas como la nieve, te diré que la que no una sola ceja tiene, bigote bajo las narices le asoma, bizca es o patizambos sus andares cuando el camino que toma muestran unas posaderas que son todas de hueso, y que no acaba en unos pechos lisos todo eso, pues bajo pañuelos y tocados ocultan la que menos una calva y la que más un cuerno. Dime si no tengo razón al asustarme ante ese infierno que es el haber catado hembra noble en carnes y trato, mas no en condición, y verme abocado a resignarme en un futuro no lejano con el espantajo que te acabo de ilustrar.

Exageradas le parecieron a Sastenillo las descripciones del caballero, aunque no le faltaba razón al decir que entre las mozas del pueblo y las hijas de los nobles no había comparación. Y le dijo lo siguiente:

- No os aflijáis señor, pues no todo está perdido. A mis oídos han llegado las noticias de que en la cercana Villa de Franqueza, guarda su señor como un tesoro a su única hija, criatura noble que encarna la Belleza y cuyo porte atesora todo aquello que anheláis. Mas existe un problema: dicha dama todo lo que tiene de hermosa lo es de estre- 
cha y mucho me temo que no tardará mucho en hacer votos de religiosa pues, a todo aquel que su corazón ha pretendido sin remilgos despechado ha sido sin reparar ésta en gallardía, fortuna o nobleza del enamorado. Diriase que es de piedra, en vez de carne y hueso.

- Y bien, ¿acaso pretendéis que me estrelle yo también contra ese muro?

- Bien os podría pasar pero, si actuáis con disimulo y os mostráis tan frío como ella, tal vez en el engaño que he inventado podría caer.

- ¡Contadme, pues!

- Tengo entendido que un grupo de señores, los más orates y brabucones de los alrededores, pretenden unirse a un tal Arturo, que de Inglaterra es rey, a conquistar Tierra Santa. Si vos le hacéis ver que, para merecer su amor, os vais a matar moros, ¿quién os dice que os negará para cuando regreséis el tesoro que tantos otros pretendieron?

- ¡Y que me corten el pescuezo!

- Mas no tenéis que preocuparos: por un tiempo os escondéis y, como seguro que los que a la Cruzada van caerán muertos, un buen día os presentáis, vivo y victorioso, a reclamar vuestro premio.

Meditó sobre esto Ruinuño largo tiempo y, no pareciéndole mala idea, fue en persona a conocer a la bella Casta, sucediendo lo que a continuación se cuenta.

\section{DE LA CONVERSACIÓN HABIDA ENTRE EL CABALLERO RUINUÑO Y LA BELLA CASTA Y DONDE SE RESUELVE EL DESTINO DE ESTE}

Así que tomó Ruinuño la decisión de ofrecer sus respetos a la desconocida Casta y pedirle -si lo que viese mereciera la pena- su mano en matrimonio. Presentose Ruinuño primeramente al dueño del castillo y padre de la niña, haciendo uso de tales alharacas que diriase que conocía al Conde de toda la vida. Tal muestra de afecto al señor puso sobre aviso: ya se adivinaba a lo que el mozo venía. Mas siguióle la corriente, pues tan seguro estaba en la suerte que esperaba al aspirante que en el fondo lástima le daba.

Una vez hechas las presentaciones, hizo llamar el Conde a su hija. Esperaba Ruinuño la llegada de la dama con tal impaciencia que las piernas le temblaban, y no reparó en esto de cautivo que estaba de sus propios pensamientos: en los últimos instantes recordaba las sutiles descripciones que de ella hizo su amigo Sastenillo:

\section{Pelo largo como capa \\ cae sobre la piel de seda \\ que apretadas carnes tapa \\ y al amante desespera.}

El anhelo del caballero era en su frente notable: una corona de perlas por su piel afloraba y en tales ansias creyó ver el Conde el fatal destino de un amor despechado que sobre el pretendiente se cernía. Mas no era su compasión hacia el dolor que acechaba al joven obstáculo alguno para disfrutar sordamente la una victoria inmediata que, como otras tantas veces, ese dia iba a conseguir. Así que, cuando apareció la inexpugnable fiera de su hija y tras una breve presentación, se fue del salón dejando solos a los jóvenes para contemplar desde un escondite habitual el desmoronamiento del aspirante.

Sin palabras se quedó Ruinuño ante la presencia de Casta, pues le pareció al caballero de una belleza tal que no era digna de este mundo: con mucho destacaba sobre las otras hembras con que estuvo y diríase que había sido concebida para ocupar el trono de la reina de las mujeres. Le parecieron las descripciones simples habladurias, y tan cortas se quedaban las alabanzas que sobre ella oyó que insultos le parecían. Quedó en tal estado de azoramiento que, de lívido, parecía un muerto y al ver que no arrancaba palabra decidióse la dulce Casta, pues la presa parecía fácil y no tenía 
todo el día. Tendióle la mano la niña a la altura de su pecho y así que se agachó el caballero para besar la mano tendida su mirada viajó de los ojos de la niña -ojos grandes y negros- a las dos redondeces morenas como dos copas de bronce que del vestido emergían. La cercanía al ángel y sus encantos produjo tal brecha en su corazón malherido que pesábale la vista como una roca y de esta suerte vio metidas sus narices en el surcio prodigioso que los senos describían. No pudo contener su asombro la doncella ante tal atrevimiento, pues la mosca muerta que ante sí tenía, al parecer, estaba viva.

- ¡Contento estaréis de vuestra osadía! Decid pronto lo que de mí pretendáis, aunque por vuestro comportamiento imagino y escrito en los ojos lo lleváis.

No habian comenzado las cosas con buen pie, pensó Ruinuño, y si difícil antes lo tenía, ahora más aún. Pues si otro, en su lugar, ya se hubiera rendido casi sin empezar, recordó el joven a su amigo Sastenillo y pensó que si éste con tanta facilidad lograba embaucar a la gente -saliendo de situaciones más comprometidas que aquella-, tal vez por el influjo de su compañía algo habría aprendido de tanta marrullería. Así que armándose de valor resolvió Ruinuño a hablar así a Casta, convirtiendo a Sastenillo en maestro de su señor:

- ¡Pardiez, fermosa doncella, que no osarían mis profanos labios de sobrepasar el límite marcado por el casto ósculo de la amistad que por vos profeso! Y si al inclinarme para besar la mano que me tendisteis rocé vuestro recatado seno con mi napia más se debería a colleja del Maligno que a rúbricos pensamientos.

- Os explicáis muy bien, noble caballero -respondió la joven-, mas detrás de tanta labia en vuestro pensamiento adivino lo que tantos otros vinieron a buscar, que no es más que mi mano a sabiendas que tras ella sigue el resto de este cuerpo.
- Mas no sé de qué cosa me habláis. Lo que yo reclamo es... ¡vuestro pañuelo!, y no esas cosas tan sucias con las que a mi intención acusáis.

- ¿Mi pañuelo? -dijo Casta contrariada-. Sin palabras me dejáis... Tan extraña es vuestra petición que sus motivos no acierto, y os ruego no os ofendáis si os pido una explicación, pues no es para aplacar una ofensa sino para sacarme de mi sorpresa.

- Esa duda que expresáis os la voy a resolver. Dentro de poco parto voluntario a la Cruzada, pues es mi deber de caballero el ofrecer mi espada para liberar Tierra Santa. Mas iqué triste empuñadura aquella que un filo mortal sostiene si en su extremo no se anuda el pañuelo de una doncella! ¡Qué triste empresa la mía, si en tierras enemigas miro el mango de la espada y en su cuero desnudo adivino la futilidad de mis esfuerzos, y es que no existe una mujer por la que matar o caer muerto! De qué sirve conquistar Jerusalén si el honor de una dama no lo va a merecer.

Sorprendióse Ruinuño al ver que dijo todo esto de carrerilla, e incluso pareció sombrío a los ojos de Casta, a la que tanta tristeza en las palabras del caballero conmovió. Pues empleó tal sentimiento que nadie diría que no era sincero.

- Me dejáis sin palabras por tan extraña petición que me hacéis... ¿Por qué recurrís a mí y no a otra dama?

- A otras lo propuse y tiempo les faltó para lanzarse, presas de la lujuria, entre mis brazos. De poco les valió a todas ellas, puesto que como hombre recto quie soy, tan malas intenciones sólo obtuvieron como respuesta la frialdad de mi indiferencia. Pues mi empresa es noble y de elevado fin; entonces, siendo esto así, ¿cómo iba a batirme en tales duelos si es para una cualquiera el fruto de mi desvelo y de mi sangre? ¡Vive Dios que quien por mi fin lucha va directo al Cielo, y que no será mujer lasciva y casquivana la que, como esposa mía o prometida -si en la lid muero-, le corresponda por derecho tan alto destino! 
Enrevesó tanto la cuestión Ruinuño que, sin. darse cuenta, si al principio pedia un pañuelo, era ahora a la dueña de este a quien su favor reclamaba. Y fueron tan sutiles sus palabras como acaloradas: tal vez por ello abrumada estaba Casta y, si al principio no iba a negarle al caballero el capricho de su pañuelo, sin negarse a ellas, tampoco ahora se pronunció en contra de las intenciones matrimoniales de éste. Meditó en silencio la doncella sobre este asunto y se dijo: "no es moco de dragón lo que este caballero ofrece, y si por ser esposa de cruzado gano el derecho a la salvación, vive Dios que no será pecado aquello que en el lecho hagamos los dos; y es más, que tal vez sea soberbia el negar también a este buen mozo aquello que tantos sudores me está costando guardar. Pues si fuera pecado el dejar que parta triste y por ello muera, tal vez mis desvelos por preservar intacto mi honor caigan en saco roto". Y ahora en voz alta se dirigió a Ruinuño así:

- ¿No tenéis miedo de que en la lid os dejen manco, cojo o tuerto, si bien antes no me dejáis viuda antes de casarme? -el titubeo de estas palabras sonó a Rutinuño como un indicio de victoria.

- No temáis, Casta, que guerrero soy forjado en mil batallas, y no será para mí enemigo de talla el moro infame. Pues si mi carne osa rozar la cimitarra sarracena, más se deberá a golpe de chiripa que de arrojo del infiel que delante de mi tenga. Pues me consta por un intimo amigo mío, que es Cardenal, que los agarenos que más allá de la Peninsula habitan, son gente enclenque, cobardes y algunos hasta sodomitas, más dados a la lectura y otras zarandajas que a cultivar la nobleza guerrera que cada hombre dentro de sí lleva.

Anonadada quedó ahora la mujer, pues resulta que aquel que delante de ella se hallaba tan magno era que no sólo conocía a un cardenal, sino que además jeran amigos!, iy encima íntimos!, y creyó Casta estar frente a un hombre que nada tenía que ver con el común de los mortales. Huelga decir que de otro modo entendió esta amistad, tal como pretendía el taimado Ruinuño que así fuera al hablar de Sastenillo con el otro sobrenombre con el que era conocido. Y dijo, la ya derrotada Casta:

- De vuestra victoria estáis muy seguro, y en tales argumentos se adivina. Más, ¿qué es eso de sodomita? ¿Acaso unas malas artes o engaños que, en pillándoos desprevenido puedan haceros daño?

Dudó Ruinuño ante estas palabras si en realidad era tan tonta o le estaba tomando el pelo.

- ¡No, no!, que es un tipo de vicio al que entre ellos son muy dados..., y de explicar sería largo.

- No es menester que sigáis. Mañana mismo iré a mi confesor por si sin yo haberme dado cuenta, por ignorancia, halla incurrido en esa falta de que habláis.

-iA buen seguro que no! -dijo el mozo, convencido ya de que era lonla, y para cambiar de tema, ahora que ya tenia ganada a Casta, sacó de una bolsa un extraño correaje con una especie de cerraja en su parte baja. Y tendiéndolo a Casta, dijo:

- Ya que al parecer aceptáis mi propuesta, permitid que os haga entrega de este cinturón que será como mi espada misma que vuestra doncellez guarde mientras esté en la batalla.

-i之Es que lo que de mí sabéis vuestras dudas no acalla, y me insultáis entregándome un cinturón de castidad, como si fuera a entregar a cualquiera lo que os corresponderá tras la boda?!

- Perdonadme, Casta..., es que me dejo llevar por la moda...

Quedó con semblante triste Ruinuño, fingiendo arrepentimiento por estas últimas palabras y Casta, sintiendo lástima de él, se acercó y acariciando y besando su mejilla, lo perdonó. Pero tal acercamiento dejó sus huellas en éste.

- Oh caballero..., parecéis tan sincero... Mas, ¿qué es ese bulto que en vuestra entrepierna aflora y os tensa el calzón? ¡Tenéis mala cara! 
- Nada, amada mía. Es que me hierve la sangre pensando en la feroz batalla que en tierras del infiel me esperan y en la dulce recompensa que será vuestro amor... ¡He de irme!

- Mas, por ahí se va a letrinas. Os veo pálido, y vais como temblando...

- ¡Porque..., me..., me estoy meando!

$\approx * * * 3$

¡Vaya si acabó yendo Ruinuño a la guerra, en contra de los planes que él y Sastenillo tenían!

Como ya se dijo, el padre de Casta permaneció escondido durante la conversación de los jóvenes. Tentado estuvo de salir de su escondrijo y degollar delante de su hija a aquel cerdo que, con tan buenas palabras, había embaucado a Casta. Pues bien sabía el Conde que las mil batallas a las que se refería el caballero habían sido libradas contra espantapájaros y enemigos similares. Mas contuvo los deseos de atravesarlo con su espada y, hallando en la inutilidad guerrera del fulano una solución menos drástica, resolvió hacer lo que a continuación se expone.

Ya sabía el Conde de la empresa de la que hablaba Ruinuño, pues conocía al promotor de esta: un viejo compañero de juergas - con el seso sin duda reblandecido por el vino- que con esta acción pretendía, como el Conde, redimirse de antiguas correrías. Intuyendo los planes de Ruinuño, se aseguró de que realmente se embarcara, acompañándolo él mismo el trecho que hizo falta y, no contentándose con esto, habló con dicho amigo para que lo mandara a primera línea de batalla, llegado fuera el caso. Viendo Ruinuño que no podía escabullirse de tan pesada vigilancia, renunció a su idea de esconderse y marchó a la guerra a pesar de los consejos de Sastenillo, pues quedó tan prendado de Casta que dio por bueno el sacrificio. Y toda la expedición acabó muerta en la batalla, excepto (burlas del destino), nuestro inex- perto caballero, que acabó con un brazo menos y hecho prisionero. Pasó varios meses con un yugo al cuello, haciendo girar como un burro una rueda de molino. Y si no murió fue porque en todo momento pensaba en su prometida.

Así estuvo dando vueltas el manco caballero hasta que, un día, de él se apiadó uno de sus guardianes y le facilitó la huida. Pasó mil desventuras hasta regresar a su tierra y, aunque son muchas las versiones que corren, parece ser que se embarcó con un mercader judío que a Aragón se dirigía, con la promesa de servirle de intermediario entre aquellas gentes desconocidas, dejándolo en la estacada una vez llegado a su patria.

\section{DEL REENCUENTRO DE RUINUÑO CON SU PROMETIDA Y DONDE, POR TODO LO ACONTECIDO, SE RECOMIENDA HUIR DE LA MUJER MOJIGATA COMO DE LA PESTE}

Llegó, como se ha dicho, Ruinuño a la tierra de sus padres, donde fue recibido con unos modestos aunque merecidos honores de héroe. Mucho habían cambiado las cosas en aquellos lares desde su partida, y más para Ruinuño pues dos años es plazo suficiente para que se haga sensible el ojo del ausente para apreciar, a su regreso, las más insignificantes mudanzas en los hombres y en las cosas. Así pudo ver cuanto había envejecido su padre -ancianidad prematura sin duda traída por los desvelos que le produjo la marcha de su hijo a la guerra-, que ahora lloraba, pero de alegría, por ver que su hijo le era devuelto, si no entero, al menos vivo. Apreció ese abandono del cuerpo del padre reflejado en el descuido del castillo y de su hacienda, en los campos y sus campesinos que ahora eran menos en número. Echó de menos a su amigo Sastenillo, que un buen día se marchó sin saber nadie a donde. Y se alegró al saber que su futuro suegro había muerto a manos de unos ladrones en su camino de regreso cuando lo acompañó hasta la cubierta misma del barco que lo tenía que 
mandar a la barbarie y a la mutilación, sin duda por sospechar un tanto de sus intenciones.

Por último visitó a su prometida, y el ver que el tiempo no sólo había respetado su sobrenatural belleza sino que aún la había acentuado más, unido a la forzada abstinencia que durante tanto tiempo hubo de mantener, hizo que Ruinuño forzara los preparativos de su boda para poder disfrutar cuanto antes del premio que tan merecidamente se había ganado.

Y así que llegado fue tan deseado día.

No fue una ceremonia de grandes ostentaciones, pues la celeridad con que se había preparado todo a ello obligó. Y es que, como se ha de intuir, pensaba el caballero más en el disfrute de su noche de bodas que en el de los invitados, los cuales al fin y al cabo no habían hecho ningún mérito como perder un brazo o ver rebajada su dignidad a la del esclavo.

Llegaron pues marido y mujer al tálamo de ambos y allí tendidos fue Ruinuño saboreando lentamente el fruto de su victoria: cada pieza del vestido era retirada por éste con oficiosa solemnidad y en ningún momento le exasperó el exceso de telas que llevaba su amada, pues tras cada una que retiraba podía apreciar un pequeño milagro que, si a veces era un olor o una promesa, otras era un trecho de carne: aquella piel que era esa noche su auténtica patria y por la que con tantos sufrimientos se había batido. Y daba gracias a Dios con cada nuevo hallazgo el haberle permitido el vivir para ser aquella noche el gineceo de tan hermosa mujer.

Mas llegó Ruinuño al meollo de la cuestión y con gran desesperación vio que el sello que tenía que abrir allí no estaba, señal indudable de que otro se le había adelantado.

- iiTendréis una explicación!! -dijo, iracundo, el ofendido, mas sólo obtuvo de su esposa una mirada boba que admitía los hechos¡Vaya con la niña casta, vaya con la mosca muerta...! ¡Decidme quién fue, que vive Dios lo he de matar! ${ }_{i} \mathrm{Hablad}$, antes de que haga lo mismo con vos!!

Se recogió Casta sobre sí misma, mínima, desnuda, y no lograba el miedo que sentía por la ira de su marido difuminar un solo ápice de su belleza.

- Fue..., fue el bufón.

- ¡Con el bufón! Y yo que me creí tan listo al haceros caer en las redes del amor, y llega un simple bufón y jtoma!, lo que a mí casi me cuesta la vida conseguir, lo obtiene otro con menos sufrimientos, sin duda . ¡Pues nada, iré a cumplir mi promesa! -dijo, dirigiéndose hacia su espada.

- ¡Esperad! -dijo Casta-. En tal caso habréis de comenzar por el sastre, el cocinero y el cabrero...

- Pero... jtodos esos!

-Y otros tantos más, de los cuales no me acuerdo. Mas de todos fue el primero un simpático eclesiástico que es cardenal, quien tras la muerte de mi padre vino a consolarme con sus palabras y, con tanta pasión hablaba que mi afligido corazón levantaba y, siendo como era hombre santo, no me pude negar.

Ya sabía Ruinuño que aquel cardenal del que hablaba no podía ser otro que el sagaz y embaucador Sastenillo, quien atraído por el desconsuelo de tan hermosa dama vio la oportunidad de conseguir lo que a otros tantos sufrimientos les costara. Y que, sin duda alertado por la noticia de su regreso abandonó aquellos lugares, convencido de que si una vez su amigo le perdonó la vida, no lo haría en una segunda ocasión.

- Marchaos, por favor -dijo ahora más sosegado el caballero-Dejadme solo, que aunque no me falten las ganas siento un peso tal en la cabeza que no podría terminar lo comenzado. Y no temáis por vuestra vida, ni por la de los que os amaron, pues si es cierto todo tendría que hacer tal escabechina que me quedaría solo. No os culpo a vos ni a ellos, sino a esta pasión que me ha privado del sano entendimiento y arrebatado el corazón. 
Marcharé de estas tierras y no os veré jamás. Ocultaré mi vergüenza donde nadie me conozca. ¡Pero no me iré sin antes deciros que no hay ramera más grande en toda la tierra castellana que por su favor me exija dos años de mi vida, un brazo y soportar vejación!

Así quedó Ruinuño, solo, meditando su desgracia en una habitación cada vez más oscura y fría. Dicen unos que allí mismo finó de pena; otros, que él mismo se dio muerte. Mas lo cierto es que no ocurrió nada de esto, sino que, por el curso de sus cavilaciones, entró en un estado de tal paroxismo que alertó a todos los criados, los cuales lo vieron desnudo y tendido en el suelo lanzando tales carcajadas que lo tomaron por loco. Y no era aquella una risa de locura sino de total lucidez, pues era la Razón la causante de tales risas. Pues se reía el caballero de sí mismo, el más tonto de toda la historia, al repasar los hechos y darse cuenta de que, después de tantos desvelos, folgar, no folgó.

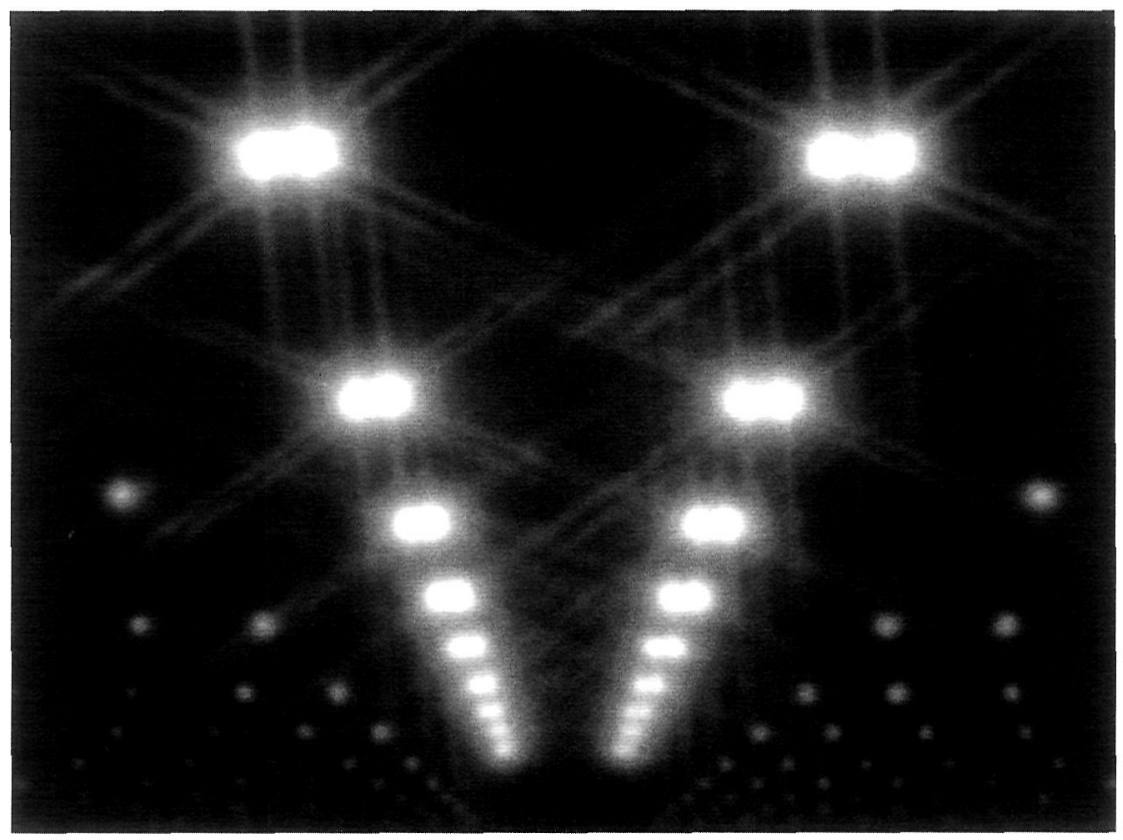

